This item was submitted to Loughborough's Research Repository by the author.

Items in Figshare are protected by copyright, with all rights reserved, unless otherwise indicated.

\title{
The digital society and provision of welfare services
}

PLEASE CITE THE PUBLISHED VERSION

https://doi.org/10.1108/IJSSP-05-2017-0062

PUBLISHER

(C) Emerald Publishing Limited

VERSION

AM (Accepted Manuscript)

PUBLISHER STATEMENT

This work is made available according to the conditions of the Creative Commons Attribution-NonCommercialNoDerivatives 4.0 International (CC BY-NC-ND 4.0) licence. Full details of this licence are available at: https://creativecommons.org/licenses/by-nc-nd/4.0/

\section{LICENCE}

CC BY-NC-ND 4.0

\section{REPOSITORY RECORD}

Pedersen, John S., and Adrian Wilkinson. 2019. "The Digital Society and Provision of Welfare Services". figshare. https://hdl.handle.net/2134/32753. 
Virum, 9/8-17, jsp. FV

\section{Does the digital society result in a new model of the provision of welfare services having new participatory spaces for actors?}

\section{Introduction}

The digital society has been announced (Lupton, 2015), and has already established a position in the zeitgeist of modern society. The digital society has emerged from and developed further via: digitising, online information in almost real time, algorithms, datainformed decision-making processes, data-driven management and, ultimately, big data. We expect to see further digitising, more sophisticated algorithms and more big data. We suggest that a new model of the provision of welfare services to citizens will emerge from the development of the digital society. We also suggest that this new model will compete with the classic model of the provision of welfare services. In the modern world, citizens face issues with health, disability, caretaking, pensions, unemployment, education and many more. To help them deal with these issues, citizens demand services provided by service professionals: teachers, pedagogics, social workers, doctors, dentists, nurses and others. Historically, professionals are seen as experts, given their established training and experience, and citizens follow the advice and services provided by them.

The claim and promise of the digital society is that it will improve almost all important aspects of life (Lupton, 2015; McKinsey Global Institute, 2011). One reason relates to mobilising and optimising the utilisation of resources. Furthermore, professionals and their (middle) managers are made more accountable for their performances as the 'audit society' (Power, 2007) is digitalised. Research on the impact of digitising on professionals and their managers and how professionals and their managers react to digitising has been neglected, despite the plethora of work on digital data (Buffat, 2015). Digitising, online information in almost real time, algorithms, data-informed decision-making processes, data-driven management and, ultimately, big data seem to fit neatly in another management fashion: that of evidence based management (Morrell and Learmouth, 2017). This type of management incorporates the use of the best available scientific evidence from peer-reviewed sources and the systematic gathering of organisational facts, indicators and metrics to act better on the evidence and practitioner judgement, assisted by procedures, practices and frameworks that reduce bias, improve decision quality and create more valid learning over time. In evidence based management, decisions are made explicit to reduce decision neglect (not making a decision that needs to be made), to avoid making decisions on auto-pilot (important actions taken without deliberation) and to increase mindful, deliberate decision-making. The process of making decisions explicit has two parts. The first aspect is developing decision awareness, recognising the numerous micro-choices made every day, all with the potential to be informed by evidence. The second feature of making decisions explicit involves actually beginning to pay attention to how a decision is made, with whom and with what evidence (Rousseau and Barends, 2011). 
The aims of this paper are, first, to explain why a new model of the provision of welfare services to citizens arises from the digital society. Second, we explore some core elements of the competition between the new model of the provision of welfare services and the classic ideal model of the professionals' provision of welfare services. Third, we suggest why it is most likely that the two models of the provision of services are combined into a symbiotic coevolution scenario. Fourth, we examine why and how this symbiotic co-evolution scenario results in new participatory spaces for the main actors associated with the provision of welfare services.

\section{Analytical framework}

Drawing on the literature concerning professions, it is possible to define the classic ideal model and practice of the service professionals' provision of welfare services directly to citizens as end-users. Drawing on Lipsky's (1980; 2010) classic analyses of street-level bureaucrats; Mintzberg's (1983) studies of professional bureaucracy; Thornton, Ocasio and Lounsbury's (2012) institutional order of Profession within the Interinstitutional System Ideal Types; Lerborg's (2010) public service professionals' paradigm of the provision of welfare services; Schön's classic (1991) analyses of 'the reflective practitioner'; Polanyis' (2009; 1966) investigations of 'the tacit dimension' in professions; and, Fledderus et al. (2014) analyses and discussions of trust, co-production and public services, it is possible to define the classic ideal model and practice of the service professionals' provision of welfare services to citizens. This model and practice consists of four steps:

First step. Each service professional assesses through dialogue each citizen, the citizen's issues and needs for services.

Second step. Service professionals provide citizens with the best services to address citizens' issues/needs. The provision of services is performed in accordance with the values, norms, standards and (cultural) traditions of the profession.

Third step. Service professionals organise feed-back mechanisms to enable the comparison and evaluation of the predicted impacts of the services provided with the actual impacts on the citizens' issues/needs.

Fourth step. Service professionals engage continuously in personal learning on the basis of the organised feed-back mechanisms. The aim of this is to improve the ability to match citizens' issues/needs with service provision. It is proposed that this aim is possible due to the iterative nature of the four steps, allowing the generation of a permanent circular learning spiral.

If we define citizens as c1, c2, c3, c4.....cn, the citizens' issues/needs as minuses -i1, -i2, -i3, $-\mathrm{i} 4, \ldots .$. -in and the professionals' provided services as pluses $+\mathrm{s} 1,+\mathrm{s} 2,+\mathrm{s} 3,+\mathrm{s} 4, \ldots \ldots+\mathrm{sn}$, we shall have a situation close to zero / 0 , given the professionals' feed-back mechanisms and learning spiral. Of course, point zero / 0 is never reached in practice due to the flow of the citizens' issues/needs in reality and the development of new issues/needs among citizens. The service professionals' classic ideal model and praxis is illustrated in Figure 1. 


\section{Figure 1. The service professionals' ideal model and practice of the provision of welfare}

services

The four steps in the professionals' ideal model and practice of the provision of welfare services directly to citizens are found in Figure 1. Boxes 1-3 reflect the first step, boxes 4 and 5 reflect step two, box 6 reflects step three, and boxes 7 and 8 step four. The arrows in Figure 1 illustrate that the four steps are iterative, allowing the generation of a circular learning spiral for professionals.

Figure 1. The service professionals' ideal model and practice of the provision of welfare services

1: Citizens' issues, needs / wishes (regarding job, health, education etc.)

\begin{tabular}{|c|c|c|}
\hline \multicolumn{2}{|c|}{$\begin{array}{l}\text { 3: Professionals' dialogue based discretion } \\
\text { of the individual citizen's issues/needs }\end{array}$} & $\begin{array}{l}\text { 4: Provision of services in } \\
\text { accordance with professions' } \\
\text { norms, standards, values and } \\
\text { culture }\end{array}$ \\
\hline \multirow{2}{*}{\multicolumn{2}{|c|}{$\begin{array}{l}\text { 2: Professionals / social workers, pedagogics, teachers, } \\
\text { nurses, policemen and other groups of professionals }\end{array}$}} & \\
\hline & & $\begin{array}{l}\text { 5: Co-production / delivery of } \\
\text { services directly to the citizens } \\
\text { as end-users }\end{array}$ \\
\hline \multicolumn{3}{|c|}{$\begin{array}{l}\text { 8: In principle, professionals increase skills in provision of } \\
\text { services = Increase skills in matching services with } \\
\text { citizens' issues / needs / wishes }\end{array}$} \\
\hline $\begin{array}{l}\text { 7: Individualistic organizing of learning and } \\
\text { enhancement of body of knowledge on the basic } \\
\text { of tacit knowledge }\end{array}$ & & $\begin{array}{l}\text { 6: Feedback mechanisms = Typically } \\
\text { organized as individual evaluation of } \\
\text { linkages between issues / needs/ } \\
\text { wishes; estimated effect and realized } \\
\text { effects }\end{array}$ \\
\hline
\end{tabular}


Professionals must, according to the aforementioned literature on professions, have autonomy to exercise discretion in their daily operations. Professionals cannot provide citizens with the best possible welfare services without autonomy and the right and obligation to exercise discretion in daily operations regarding citizens' issues/needs and services to address issues/needs. Jespersen and Wrede (2009: 155-156) refer to the professionals' autonomy presented here as 'traditional professional autonomy'. Within 'traditional professional autonomy', professionals have both a monopoly on particular jobs and specific management positions in service organisations. Professionals have the so-called double social closure. As a result of this, professionals have the authority to define and address citizens' issues. This raises a key question: what role does management play in the ideal model and practice of the service professionals' provision of welfare services to citizens? In the standard literature on professions, the role of managers is to empower professionals in daily operations through recognition, appreciation and support (Andersen and Pedersen, 2014; Bevort et al., 1992, Lerborg, 2010; 86-94). This is illustrated in Figure 2.

Figure 2. Managers in the classic ideal model and the practice of service professionals' provision of welfare services to citizens as end-users

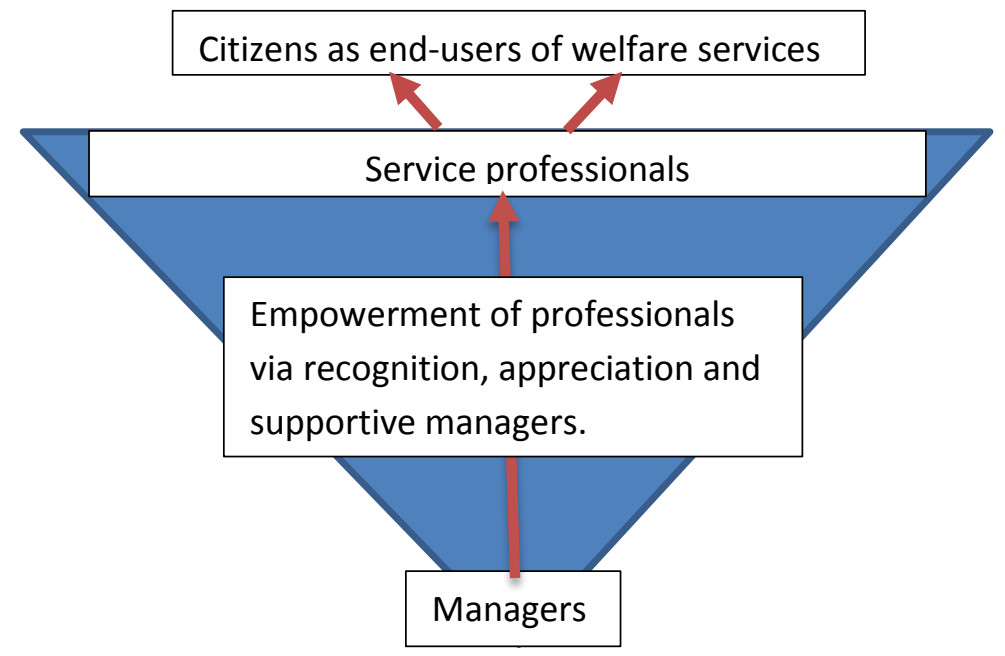

In line with the aforementioned double social closure, service professionals and managers who have worked many years in the daily operations as front-line professionals form a kind of partnership or strong alliances in the classic ideal model and practice of the professionals' provision of services. This theoretical claim is backed by empirical research (Klausen, 2006; Pedersen, 2007).

The classic ideal model and practice of the professionals' provision of service has blind spots similar to many other models and practices (Lerborg, 2010). One such blind spot is economic efficiency in daily operations. Economic efficiency is not usually the most important 
consideration for a professional (Thornton et al., 2012: 73). This can result in differences in opinions and objectives for managers and professionals, “...values about being economical or even efficient seldom loom large among the professionals, which can easily mean that what managers regard as a good result and what professionals strive to achieve are by no means the same thing...” (Brunsson, 2009: 62).

Some researchers claim that the digital society, that is, digitising, online information in almost real time, algorithms, data-informed decision-making processes, data-driven management and, ultimately, big data, can remedy this and other blind spots of the classic model (McKinsey Global Institute, 2011), by digitising 'the audit society'. If this is correct, the digital society challenges the classic ideal model and practice of the professionals' provision of welfare services to citizens. However, it is not likely that the digital society will replace the classic ideal model and practice with a whole new one. One reason for this relates to the institutional logics perspective. From this perspective (Lerborg, 2010; Olson, 2006; Pedersen and Aagaard, 2015; Røvik, 2002 and Thornton et al., 2012), no institution, no logic, no (management) paradigm, no model and practice, and no super-standard/super-recipe can dominate all other institutions, logics, or so forth. Due to this, it is most likely that the classic model and practice will be modified, albeit significantly, by the digital society's model of the provision of services. According to the institutional logics perspective, it is most likely that the classic ideal model of the professionals' provision of services and the digital society's new model of the provision of services will be combined due to 'transposition' (Thornton et al., 2012: 62). That is, elements from the two models' considered logics will be exchanged and both models will be modified. From this perspective, it is most likely that both models will exist and develop further in a 'symbiotic co-evolution' (van Buuren et al., 2009). It can be argued that such a scenario opens new participatory spaces for actors associated with the provision of welfare services directly to citizens as end-users. Moreover, it can be argued that these new participatory spaces could turn into arenas for negotiations among actors (McAuley, 1994; Strauss et al., 1964), involving a new language and point of engagement (Oswick et al., 1997:6).

The next section focuses on blind spots of the classic model, followed by a discussion of how this creates new participatory spaces for actors to engage and co-construct the new logic/paradigm.

\section{Blind spots, digital society and a new model of the provision of welfare services}

At least four blind spots can be identified in the classic ideal model and practice of the professionals' provision of welfare services. These include: 1) economic efficiency in daily operations; 2) loyalty; 3) the documentation of the provided services' impact on citizens' welfare; and, 4) learning as anticipated.

The first two relate to the professionals' higher loyalty to their professions' norms, standards and values than to political, political-administrative and top-managers' decisions, which results in prioritising services to citizens over economic efficiency in daily operations and 
loyalty to third parties (Brehms and Gates, 1997; Brunsson, 2009: 61-62; Harrits and Møller, 2014; Lipsky, 2010: 221 - 229; Riccucci, 2005 and Winther and Nielsen, 2008: 103).

The third blind spot relates to the fact that the professionals' (social workers, pedagogics, teachers, nurses and similar groups), documentation of the provided services' impact on citizens' welfare is typically scant. Clear-cut evidence of the provided services' impact on citizens' welfare is a rare phenomenon. The inability to demonstrate the effects and costeffectiveness of the provision of services has been one important driver behind the development of 'the audit society' (Power, 2007), and the present trend of evidence based management (Morrell and Learmouth, 2017). Here, the aim is not to take professional views at face value, since not only do they have weak evidence for their prescriptions, but they also disagree amongst themselves. This approach to professionals has resulted in increasing concern that, using the terminology of the philosopher David Hume, they are self-interested egoists, knaves rather than noble altruists (knights), defending the public service ethos (Le Grand, 2003).

The fourth blind spot refers to the imperfection of the professionals' anticipated learning spiral, presented in section 2. Kahneman (2011) and Kahneman and Klein (2009) show that professionals tend to exaggerate their skills regarding the assessments of citizens' issues/needs and the provision of services to address these. Moreover, the professionals' autonomy and, consequently, individualistic experiences and learning, result in tacit knowledge as the norm of the body of knowledge of professionals, where only intuition or gut feelings emerge to guide professionals in making appropriate assessments and decisions.

The digital society can, in principle, remedy the four blind spots of the classic ideal model and practice of the professionals' provision of services. The main reason relates to four key elements and specific combinations of these:

1. Digitising results in infinitely increasing online data in almost real time from multiple sources including: 1) citizens' use of the internet, social media, applications and the like, 2) various types of surveillance of individuals and groups, 3) data brokers who produce and sell large data sets on specific issues associated to specific groups, and 4) access to public sector data on citizens (Lupton, 2015; McKinsey Global Institute, 2011).

2. Online data in almost real time can add up to big data defined as “...high volume, high velocity, and/or high variety information assets that require new forms of processing to enable enhanced decision making, insight discovery and process optimization” (Svetlana Sicular, Forbes, March 27, 2013. www.forbes,com/teck).

3. Data analytics can process/mine big data via algorithms which result in predictions to be utilised in the decision-making processes. For example, how will women change shopping patterns when they become pregnant, and which retail products are most popular after a blizzard and flu epidemic? How can logistics be optimised in air transportation or at hospitals? It is important to highlight here that predictions rooted in big data and algorithms are correlations not demonstrated cause and effect linkages. 
4. Of course, the closer to real time and the more accurate predictions are, the higher value these have for individuals and entities, like firms, public welfare organisations, interest groups and others. Therefore, feedback mechanisms are an integrated element in data analytics' algorithms. To make predictions more accurate over time, these are continuously compared with outcomes as close as possible to real time. Predictions of how women will change shopping patterns when they become pregnant and predictions of how the logistics of air transportation can be optimised, are compared with pregnant women's real shopping patterns and the real optimisation of the logistics of air transportation. Due to such fact-based feedback mechanisms, documentation and learning are an integrated element in data analytics' algorithms used to mine big data. The main restriction on this type of documentation and learning is that they must come through bits and bytes; they must relate to explicit knowledge only.

These four key elements or building blocks in the digital society have the potential, if combined in specific ways, to link better service professionals' 1) assessments of citizens' issues/needs, 2) provision of services to address citizens' issues/needs, 3) feed-back mechanisms regarding documentation of the impact of services on citizens' welfare and 4) learning via the learning spiral presented in section 2. Formulated alternatively, the four key elements have, in specific combinations, the potential to enable the service professionals' classic ideal model of the provision of welfare services directly to citizens as end-users to work. However, if this becomes the case, service professionals will be pushed out of the provision of welfare services. Why? There are several reasons. The four key building blocks relate only, as mentioned, to explicit knowledge which can be expressed via bits and bytes. In contrast, the service professionals' core knowledge is, as aforementioned, rooted in tacit knowledge, meaning that each service professional at the end of the day processes and stores his or her personal experiences himself or herself. This is why service professionals know (much) 'more' than they can articulate or show (Polanyi 1966; Schön 1991; Baruchello 2016; Nonaka; 2007). This 'more’ (e.g. intuition or gut feelings) will become redundant in the provision of services if the four key elements dominate the provision of services. If tacit knowledge is pushed out of service provision, a defining characteristic of the classic ideal model of the professionals' will also be pushed out. Furthermore, if the tacit knowledge is replaced by explicit knowledge and this explicit knowledge is linked to the four key elements, service professionals will be told by data-analytics on behalf of (middle) managers which issues/needs the citizens have and which services have to be provided to citizens to address their issues/needs. In Jespersen and Wrede's (2009: 155-156) analysis of service professionals' autonomy, this is termed 'framed autonomy'. 'Framed autonomy' implies limited autonomy for service professionals and an emphasis on service professionals' accountability including documentation and economic efficiency. Importantly, the elements in 'framed autonomy' result in the professions' values, norms and standards becoming subordinate to the organisation and to management. 'Framed autonomy' combined with a digitalised 'audit society' results in a digitalised version of the classic top-down management pyramid as a framework of conditions for the provision of services to citizens. 
We can use a Danish case to illustrate this. In Denmark, because of the Danish (Scandinavian) universal welfare state (model), almost all-important welfare services are provided to the citizens by service professionals working in public welfare institutions public schools, public hospitals, public homes for elderly and disabled citizens etcTo promote and advance digitising in the public sector in Denmark, a 'digitalisation reform' has been underway for two decades (Greve, 2012; Pedersen, 2010). The reform is a key element in a wider agenda to make Denmark, as a very small country, competitive in the EU and in the global economy. The reform has been successful. Denmark is ranked as number 1 in EU and number 5 in the global economy, according to the EU-Commission's Digital Competitiveness Ranking Index (DESI), 2017 and IMD’s Ranking Index: Digital Competitiveness Ranking Index, 2017, IMD.

In the Capital Region of Denmark, it was decided politically to opt for data-driven management as key tool in management. Data-driven management in this region is designed and deployed top-down regarding organisational performance, which includes the region's hospitals. However, treatment of patients is not part of data-driven management in the Capital Region. Treatment of patients is conducted in accordance with the medical staff's own standards and manuals rooted in internationally acknowledged medical standards and manuals for treatment of patients. The region's politicians and political-administrative system have decided that data-driven management in the region's hospitals regarding organisational performance must focus on these five topics: 1) User-satisfaction, 2) Delivery, 3) Quality, 4) Management \& Employees and 5) Economic efficiency. The hospitals in the Capital Region have implemented and conduct data-driven management slightly differently. In the hospital, which has implemented and conduct the region's data-driven management in the most advanced and consistently way, multiple norms are negotiated and agreed (within the five topics) : norms for acceptable levels of waiting time before patients are treated, norms for treatments per unit per week, norms for nurses' hand hygiene, norms for levels of user satisfaction, norms for reporting near misses, norms for keeping budget/treatment and many more norms. The hospital's units are provided each week with actual data on performance related to the agreed norms. The data are provided by an office employing specialists in hospital-data and the data provided has been suitably processed to ensure that it is accepted by all units as valid. All data-sets are made public and aggregated to show the hospital's overall performance and compared this with the performance contract the hospital has agreed with the Capital Region. If a unit (and the hospital in general) has, which very often is the case, negative gaps between agreed norms and actual performance, the gaps must be closed. This has to be done in accordance with a manual, which describes step-wise how to close gaps. As part of the hospital's data-driven-management, gap-closing is monitored. Seen in this perspective, data-driven-management is an almost online digital top-down management tool to increase permanently the units' and the hospital's performance. As an essential and integrated part of this type of data-driven management, focus is also on the four blind spots of the classic ideal model and practice of the service professionals' provision of welfare services to citizens. That is as part of the hospital's data-driven management focus is on 1) economic efficiency in the daily operations and 2) 'hard' documentation of the provided services and the services' impact on citizens' welfare. Besides, 3) learning as anticipated in the service 
professionals' model is monitored and controlled by the manual for gap-closing combined with the weekly 'hard' performance data provided by the 'data-office' . Finally, 4) within the hospital's type of data-driven management, service professionals' loyalty to agreed norms are automatically monitored and controlled down to the single nurse's washing hands due to the design of the logging of activities. This design of logging activities is, of course, controversial. At the time of the research, data-driven management at the hospital in question is not use to single out individuals but only units and in some cases teams within (sub)units.

In Denmark, several attempts to design and implement data-driven management in the social sector have been made over the last two decades without (much) success (Pedersen \& Aagaard, 2015). In contrast to medical staff, social workers have less of a tradition for evidence based provision of services to citizens - to disabled citizens, socially vulnerable families and children, unemployed citizens and other weak social groups in society - and are hostile towards both data-driven management and data-analytics. Data-driven management and data-analytics are considered as an immediate and direct threat to the social workers' existing autonomy in the daily operations and to this related power also in the daily operations. As a result of this, data-driven-management is implemented and conducted much more at hospitals compared to other public welfare institutions in the Danish welfare state.

A digitalised model of the provision of welfare services is illustrated in Figure 3.

Figure 3. The provision of services to citizens as end-users in a digital society

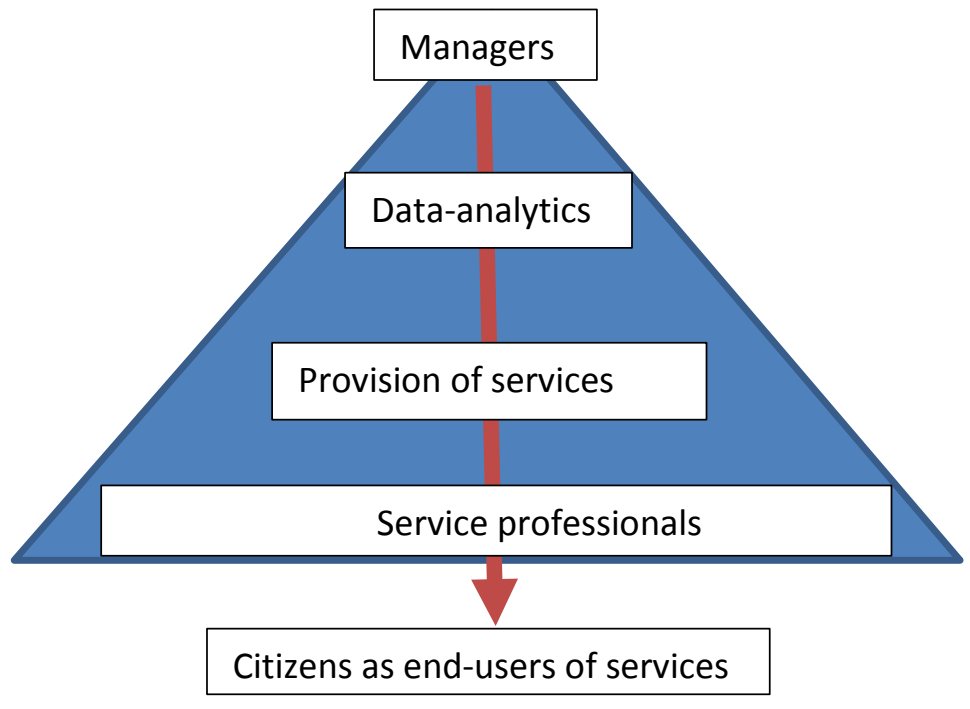


Why not opt for this model of the provision of services to citizens? One blind spot is ethics (Lupton, 2015). The model may violate privacy, and change significantly the power relations between citizens and state and between citizens and big corporations in favour of the state and the big corporations. Another blind spot is the exclusion/inclusion of citizens from/into the model. Citizens, who have limited skills in IT and restricted access to IT equipment, may be excluded from joining the model because a key element in the model is self-service (Breit and Salomon, 2015). That is, the model may create (more) inequality among citizens. The model also disempowers some and empowers some other individuals and entities, such as firms, public institutions, governments, interest groups and others. Individuals and entities who do not control algorithms, templates and digital infrastructures are disempowered by individuals and entities which do control them (Lupton, 2015). Here control is defined as the power to include and exclude individuals and entities into/from communities in cyberspace, ranking lists, access to digital information and knowledge. Another blind spot is that data analysts, the model's key professionals, are back-office professionals in contrast to the classic service professionals who are front-line professionals. The result of this is that the model simply cannot function without the classic service professionals. At the end of the day, the classic service professionals are needed to some degree. The classic service professionals shall still, as front-line professionals shall in all service organisations, realise the 'moment of truth'. The classic service professionals shall also, and very importantly, supervise the dataanalytics' algorithms (Kahnemann and Klein, 2009). Do the algorithms result in appropriate decisions regarding the provision of services? Furthermore, the classic service professionals shall push the data-analytics to make the algorithms better by asking relevant questions regarding the provision of services and service production.

The blind spots of the model of the provision of services in the digital society, and in line with the institutional logics perspective referred to in section 2, make it most likely that the classic ideal model of the professionals' provision of service will be combined with the digital society's model. It is most likely that the two models will co-exist and develop in a symbiotic co-evolution (Van Buuren et al., 2009), involving competition and conflicts. A symbiotic co-evolution scenario may be reinforced by the 'democratisation' of data-analytics' algorithms, data-sets and tools. Many will get access to data-analytics' algorithms, data-sets and tools via self-help systems and tool-boxes on the internet (Whelan, 2012). This makes it possible for the classic service professionals to empower themselves significantly, in terms of more relevant information, larger bodies of explicit knowledge, more appropriate decision- 
making processes and better learning possibilities. Classic service professionals may find themselves in a position where they can return fire in the competition against data-analytics.

In a symbiotic co-evolution scenario, it is likely that the focus will be on minimising the blind spots of the classic ideal model of the professionals' provision of services. The focus could be, in line with a digitalised version of 'the audit society', on minimising blind spots including: 1) economic efficiency in daily operations, 2) documentation of the provided services' impact on citizens' welfare, 3) learning as anticipated and 4) loyalty. Regarding the latter, it is notable here that data-informed decision-making can control professionals down to the single professional's daily activities including the decisions they make and, by so doing, control how loyal professionals are to the decisions of political and political-administrative systems and mangers (Pedersen, 2016). We suggest that data-driven management can be seen as a tool to create a focus on these blind spots in a symbiotic co-evolution scenario which opens new participatory spaces for actors associated to the provision of services to citizens.

\section{Data-driven management, blind spots and new participatory spaces for actors}

Data-driven management (DDM), defined as management rooted in explicit knowledge and extracted from the four aforementioned key elements of the digital society via data-analytics' algorithms, is proposed to be an efficient tool to minimise the blind spots of the classic ideal model of the professionals' provision of service.

Deming and Drucker (2012; 10), Provost and Fawcett (2013: 53), McAfee and Brynjolfsson (2012) and McKinsey Global Institute (2011) claim that DDM, as defined above, can increase performance significantly in firms' marketing, sales, logistics, recruitment/HRM and innovation. This claim is applicable to public welfare organisations (Lupton, 2015; McKinsey Global Institute, 2011; Pedersen and Aagaard, 2015). Consequently, DDM has the potential to minimise the blind spots of the classic ideal model of the professionals' provision of service regarding economic efficiency in daily activities. Due to this, DDM has become big business and big money (Lupton, 2015), and has upgraded data-analytics to the sexiest job of the 21st century (Davenport and Patil, 2012).

The more 'the audit society' (Power, 2007) is digitalised, the more possible documentation of the provided services' impact on citizens' welfare, based on explicit knowledge, becomes. Consequently, DDM, in a digitalised version of 'the audit society', has the potential to reduce the blind spot regarding documentation. Because the documentation of the services' impact on citizens' welfare in a digitalised 'audit society' is based on explicit fact-based knowledge available online in almost real time, it becomes possible to create a learning spiral, as anticipated in the classic ideal model of the professionals' provision of service. DDM can create reliable feedback mechanisms regarding services and impacts that can generate, in services organisations, a permanent circular learning process, as anticipated in the classic ideal model of the professionals' provision of services presented in section 2. Thereby, DDM can contribute to remedying a major blind spot of the classic ideal model of the professionals' provision of service. This is also the case regarding the blind spot loyalty because professionals' activities in daily operations, including decisions made, are logged 
automatically. This makes it possible to monitor each professional's activities and decisions. By doing this, it is possible to control to what degree professionals are loyal to decisions made in political systems, political-administrative systems and by firms' top-managers (Pedersen, 2016). In the case of unacceptable gaps between processionals' activities in daily operations and managerial decisions, the gaps can be reduced by top-down DDM.

In summary, DDM can, in principle, remedy the blind spots of the classic ideal model of the service professionals' provision of welfare services to citizens as end-users.

However, DDM is also a catalyst for dynamic change in the provision of welfare services. DDM invites data-analysts, a new profession, into the provision of welfare services. Moreover, the data-analysts become the most important profession in the service provision because data-analysts define the algorithms on the basis of which services will be provided. Consequently, managers in service provision must manage both classic service professionals and data-analysts. This is, of course, a problem. Classic service professionals may compete with data-analysts in the service provision to maintain their traditional alliance with the middle managers in the provision of welfare services. Traditionally, the alliance between classic service professionals and, especially, middle managers is strong, due to the fact that most middle managers still have a background as front-line service professionals (Klausen, 2006; Pedersen 2007). However, the managers will, by necessity, be pressured to create a new and strong alliance with the data-analysts simply because they hold the keys to the provision of services in the daily operations, that is, the algorithms.

Citizens are expected to become more interactive co-producers of their own services as the digitalisation of the provision of services progresses. The international management consulting houses promoting DDM suggest that citizens will be empowered, because of the new possibilities of being interactive co-producers. The citizens, as end-users of welfare services, are supposed to have a new and stronger position in the service provision. It is worth noting here that the digitalisation of service provision excludes some citizens from the provision because of a lack of self-service IT skills (Breit and Salomon, 2015).

Given that DDM invites data-analysts, as a new profession, into the provision of welfare services, managers, classic service professionals, and citizens must have new positions in the provision of the welfare service. This, of course, creates new conflicts and alliances among the data-analysts, the classic service professionals, the managers and the citizens. These new conflicts and alliances open up new spaces for the interaction of the various stakeholders. In such spaces, data-analytics, managers, classic service professionals and citizens can consider new arenas for the negotiations of the criteria for the provision of welfare services or even arenas for negotiations of a new model of the provision of welfare services.

\section{New participatory spaces as negotiable arenas}

For a long period, there has been interest in how professionals are being increasingly 'managed', and in the context of 'performativity' (Lyotard, 1984), which emphasises accountability, the issue of ' ... how far the established professions can retain their exclusive access to and control over abstract, formalised knowledge and the operational skills and 
routines it facilitates and legitimates' (Lyotard, 1984) is one of keen debate (Cohen et al., 2002).

The traditional assumption is that there is an inherent tension and conflict between management and organisations, on the one hand, and professionals on the other (Abbott, 1988; Dawson, 1994). The suggestion is that, once professionals become employees, embedded within organisations, they will experience an inevitable antagonism between their professional interests and the ideals and demands of the organisation. Mintzberg's (1983; 1989; 1994) conceptualisation of the 'Professional Organisation', where the professional retains autonomy within the framework of the bureaucracy, and thus has '...the best of both worlds: he is attached to the organisation, yet free to serve his clients in his own way'. Mintzberg (1983: 205) sees the professional as the 'organisation prima donna' with the manager cast as a mere a facilitator enabling the professional but without any strategic or financial control (Dawson, 1994). This view has been outweighed by a contrary view which suggests that we are witnessing the 'proletarianization' of professionals as they increasingly lose autonomy and power (Aronowitz, 1973). Managers are characterised as undermining rather than enabling professional employees. It has been argued that professionals and managers have effectively 'changed places' in terms of their degree of autonomy, status and control over work (Leicht and Fennell, 2001). From a historical perspective, 'traditional professional autonomy' has been replaced by 'framed professional autonomy' (Jespersen and Wrede, 2009: 155-156) which has resulted in "elite, collaborative, managerial work ...starting to 'look like' traditional professional work on many important dimensions, and the prerogatives that elite managers have amassed for themselves since the late 1970s have placed them in positions with unprecedented decision making and authority and flexibility. Professional workers by contrast face an increasing set of organised stakeholders who question the content, quality and cost of professional work ...” (Leicht and Fennell 2001: 226).

Rather than taking the extremes of the above perspectives, we suggest that in the context of DDM it is more fruitful to see this relationship between professionals and, especially, middle managers in service provision as a dynamic and dialectic account within the notion of a 'negotiated arena' (McAuley, 1994; Strauss et al., 1964). So, we eschew a dichotomous relationship in favour of a more dynamic, and dialectic account with an interest in the ways in which members negotiate organisational realities through their different organisational and professional discourses. Examining the relationship between professions and organisations from a negotiated arena viewpoint, we acknowledge the fundamental tensions, but suggest we need to explore the more complex ways in which they coexist and interact (See Cohen et al., 2002).

DDM fits with long debated issues to do with accountability, autonomy, trust and control. Lyotard (1984) argues that managerialism has meant the replacement of a culture of exclusivity around professional work in organisations with one of performativity. This culture of performativity has seen increasing pressure upon professionals to be accountable to external actors and agencies (Dent and Whitehead, 2002), and has been presented as 
undermining 'the professional traditional autonomy'. "The ability to trust in professional judgement... becomes an elusive quality, misted by contingency and market pressures... Trust is increasingly mitigated through the process of being managed, inspected and audited by external actors and systems. The exclusivity, protection and autonomy which professions... once enjoyed is now replaced by a culture of performativity; the belief in the veracity of the apparently objective systems of accountability and measurement rather than in the subjective judgement and specialised knowledges of the individual... the knowledges and identifications which reify the new professional are to be judged worthy then not against modernist definitions of professional judgement but in the context of performativity..."(Dent and Whitehead, 2002: 3-4). If not judged worthy in the context of performativity, service professionals risk being disempowered by being transformed into screen-professionals and system-bureaucrats (Bovens and Zouridis, 2002), who are framed by managers and subordinated by data-analytics regarding the provision of welfare services in the daily activities. Are classic service professionals disempowered in this way? This may be the end of the professionals' DNA: tacit knowledge. The classic service professionals' historical power is rooted in tacit knowledge which allows professionals to know (much) more than they can articulate (Polanyi, 2009; 1966; Schön, 1991), making professional autonomy and judgement both necessary and legitimate. Framed by managers within a digitalised 'audit society' and subordinated by data-analytics, the classic service professionals' tacit knowledge does not count for much. Fact based explicit knowledge transformed into bits and bytes counts for much more.

However, the key elements of the digital society, digitising, online information in almost real time, algorithms, data-informed decision-making processes, and, ultimately, big data, can also empower the classic service professionals. If classic service professionals embrace the digital society's key elements, they can have access to more relevant information, build larger bodies of knowledge, establish more smooth and frequent interaction with citizens, and improve decision-making processes (Pedersen and Aagaard, 2015; Whelan, 2012). In other words, classic service professionals can provide citizens with better welfare services defined as a better match between the citizens' needs and the provided welfare services. The service professionals can be further empowered, if they combine the data-analytics' approach to the provision of services to citizens with their own traditional approach rooted in tacit knowledge, professional judgement and trust based co-production. Empowered, the service professionals may match the data-analytics in service provision and, by doing this, retain their position and power in service provision.

Like service professionals and managers, citizens as end-users of welfare services have access to more relevant information and larger bodies of knowledge in a digitalised provision of welfare services. This, in principle, enables citizens to balance better the asymmetrical relationships between service professionals and themselves as end-users. That is, to compensate better for the professionals' higher levels of information, knowledge and experience (Endress, 2012; Luhmann, 1968: 27). The citizens' 'enlightenment' on the basis of digital service provision has the potential to improve the dialogue between service professionals and citizens as end-users, and, consequently, enable co-production, provided 
that the citizens as end-users do not apply the information and knowledge they gain as a mean to challenge the professionals and their authority as described by Beck (1992). However, does a digitalised provision of services result in a de-personalised relationship between service professionals and citizens? It raises the question as to what happens to trust between professionals and citizens as end-users, and, consequently, to co-production. It is important to remember here that online dialogues in digital systems can contain more information and knowledge than face-to-face dialogues because these often are limited in time. Empowered citizens will start dialogues in the digital systems with the classic service professionals, the managers and the data-analytics, and engage in negotiations about the criteria for and the model of the provision of welfare services.

Which specific role data-analytics, classic service professionals, (middle) managers and citizens as end-users will play in the provision of welfare services depends on the new participatory spaces DDM opens up and on the outcome of the negotiations about the criteria for and the model of the provision of welfare services among data-analytics, managers, professionals and citizens within the new participatory spaces considered as negotiable arenas. In other words, the reciprocal positions and powers of data-analytics, managers, professionals and citizens within the provision of welfare services, and, consequently, the criteria for and the model of the provision of welfare services depend on the outcome of negotiations among these parties within the new participatory spaces DDM creates. The outcome of the negotiations is far from predetermined. Many actors are involved in the negotiations having many conflicting powers, interests, norms and values. DDM also creates a new language, agenda, and structured conversations for the negotiations making space for agency. Besides, the provision of welfare services to citizens as end-users has to be understood and analysed as both negotiated and dynamic, situated within particular socioeconomic, political and organisational contexts meaning relationships are variable, indeterminate and uncertain.

DDM's impact on the provision of welfare services is still being realised and worked out, and more empirical research is needed before it is possible to point at the most likely scenario (Buffat, 2015). However, according to our analytical framework, the institutional logics perspective, as presented in section 2, a symbiotic co-evolution (van Buuren et al., 2009) is most likely. It is likely that DDM will constitute a new logic within the provision of welfare services on the basis of which citizens as end-users could be provided with welfare services, but it is not likely that the new logic of DDM can displace the classic service professionals' model of the provision of welfare services. According to the institutional logics perspective (Thornton et al., 2012), logics will always be combined because one certain logic cannot dominate all other logics in society (Pedersen, 2017). Therefore, it is most likely that the new logic of DDM will be combined with and integrated into the existing logics within service provision, such as the Weberian bureaucracy, the Street-Level bureaucracy, the New Public Governance and the Market (Pedersen and Aagaard, 2015). In spite of this, DDM can successfully be promoted by international management consulting houses as a super-recipe or super-standard (Røvik, 2002:113), as a management concept which can remedy all the problems of the classic service professionals' model of the provision of welfare services to 
citizens. DDM can easily become the trend for a period among managers until a new and more promising super-recipe or super-standard is offered to them by the same consulting houses. These now new super-recipes or super-standards will, in spite of becoming the trend for a shorter or longer period among managers, also be combined with and integrated into the existing logics which again and again reflect a change in the reciprocal relationships (positions and powers) among the main actors involved in the provision of welfare services (Pedersen, 2017; Røvik, 2002).

Digitisation creates a new language and point of engagement and, as Oswick and colleagues (1997: 6) assert, 'language does not merely "name” or passively describe reality, but frames it, and in so doing promotes particular attitudes and discourages others'. Management is not just technical but social (Wilkinson et al., 2017). And the managerial task becomes one that involves establishing control over the meaning of work, as much as the execution of tasks. It involves "becoming aware, attending to, sorting out, and prioritizing an inherently messy, fluxing, chaotic world of competing demands that are placed on a manager's attention" (Chia, 2005: 1092). Accordingly, big data is likely to be the subject of debate as to the meaning of it and how it should be operationalised. The issue is not whether big data but how big data. Writers such as Engestrom (1987) suggest that meaning is not constrained by design but actually forged out of usage so this is consistent with our argument of a negotiated sphere but also noting that big data and its link with evidence based practice carries a powerful discourse which makes it difficult to reject although it is open to interpretation. Equally tension which is at the heart of new ideas can propel progress and what Engestrom terms expansive learning. Our proposition is that there will be a symbiotic co-evolution and a new relationship between professionals and (middle) managers in service organisations leading to a blend of the classic ideal model of the service professionals' provision of services and ae digital society's model of the provision of services.

\section{References}

Abbot A (1988). The System of the Professions. Chicago and London: University of Chicago Press.

Alford J (2014). The multiple facets of co-production: Building on the work of Elinor Ostrom. Public Management Review, 16(3): 299-316.

Andersen LB and Pedersen L (2014). Styring og motivation i den offentlige sektor. Studier i offentlig ledelse, styring og forvaltning. Copenhagen: Jurist og Økonomforbundets Forlag.

Baruchello G (2016). Considerations on digitalization in light of Michael Polanyi's tacit knowing. Paper presented at a seminar at Southern University of Denmark, Esbjerg, February 29, 2016.

Beck U (1992). Risk Society: Towards a New Modernity. London: Sage. 
Bevort F, Pedersen JS and Sundbo J (1992). 90'ernes personaleledelse - et paradigmeskift. Viborg: Systime/Gad.

Brehm J and Gates S (1997). Working, Shirking, and Sabotage: Bureaucratic Response to a Democratic Public. Chicago: The University of Chicago Press.

Breit E and Salomon R (2015). Making the technological transition - Citizens' encounters with digital pension services. Social Policy \& Administration, 49(3): 299-315.

Bovens M and Zouridis S (2002). From street-level to system-level bureaucracies: How information and communication technology is transforming administrative discretion and constitutional control. Public Administration Review, (62)2: 174-184.

Brunsson N (2009). Reform as Routine - Organizational Change and Stability in the Modern World. Oxford: Oxford University Press.

Buffat A (2015). Street-level bureaucracy and e-government. Public Management Review, (17)1: 149-161.

Chia R (2005). Book review: The aim of management education: Reflections on Mintzberg's managers not MBAs. Organization Studies, (26)7: 1090-10.

Cohen L, Finn R, Wilkinson A and Arnold J (2002). Professional work and management. International Studies of Management and Organization, 32(2): 3-24.

Davenport and Patil DJ (2012). Data scientist: The sexiest job of the 21st century. Harvard Business Review, 90(5):70-76.

Dawson S (1994). Changes in the distance: professionals reappraise the meaning of management. Journal of General Management, 20(1): 1-21.

Dent M and Whitehead S (2002). Managing Professional Identities. London: Routledge.

Engeström Y (1987) learning by expanding CUP

Fledderus J, Brandsen J and Honingh M (2014). Restoring trust through the co-production of public services: A theoretical elaboration. Public Management Review, 16 (3): 424 - 443.

Greve C (2012). Reformanalyse. Copenhagen: Jurist- og Økonomforbundets Forlag.

Grönroos C (1990). Service Management and Marketing: Managing the Moments of Truth in Service Competition. Lanham: Lexington Books.

Harrits GS and Møller MØ (2014). Prevention in the front line: How home nurses, pedagogues, and teachers transform public worry into decisions on special efforts. Public Management Review, 16 (4): 447 - 480. 
Hirvonen H (2015). Technology as a social practice in welfare service work: Technology assisted management of care professions and professionalism. Paper presented at a seminar at University of Southern Denmark, Esbjerg, October 23, 2015.

Jespersen PK and Wrede S (2009). The Changing Autonomy of the Nordic Medical Professions. In Magnussen J, Vrangbæk K and Saltman R (eds.) Nordic Health Care Systems: Recent Reforms and Current Policy Challenges. Maidenhead: Open University Press.

Kahneman D (2011). Thinking - Fast and Slow. New York: Farrar, Straus and Giroux.

Kahneman D and Klein G (2009). Conditions for intuitive expertise. American Psychologist, 64(6): 515 - 526.

Klausen KK (2006). Institutionsledelse - Ledere, mellemledere og sjakbajser i det offentlige. Copenhagen: Børsens Forlag

Le Grand J (2003). Motivation, Agency and Public Policy: Of Knights and Knaves, Pawns and Queens. Oxford: Oxford University Press.

Leicht KT and Fennell ML (2001). Professional Work: A Sociological Approach: Hoboken: Wiley-Blackwell.

Lerborg L (2010). Styringsparametre i den offentlige sektor. Copenhagen: Jurist- og økonomforbundets Forlag.

Lipsky M (1980). Street-Level Bureaucracy: Dilemmas of the Individual in Public Service. New York: Russel Sage Foundation.

Lipsky M (2010). Street-Level Bureaucracy: Dilemmas of the Individual in Public Services, 30th Anniversary Expanded Edition. New York: Russel Sage Foundation.

Luhmann N (1968). Vertrauen: Ein Mechanismus der Reduktion sozialer Komplexität. Ferdinand Enke Verlag.

Lupton D (2015). Digital Sociology. London and New York: Routledge and Taylor \& Francis Group.

Luzio G (2006). A sociological concept of client trust. Current Sociology, 54(4): 549-564.

Lyotard JF (1984). The Postmodern Condition: A Report on Knowledge. Manchester:

Manchester University Press.

McAfee and Brynjolfsson (2012). Big data: The management revolution. Harvard Business Review, October: $62-68$.

McAuley J (1994). Exploring issues in culture and competence. Human Relations, 47: 417430. 
McKinsey Global Institute (2011). Big Data: The Next Frontier for Innovation, Competition and Productivity. Report. June.

Mintzberg H (1983). Structure in Fives: Designing Effective Organizations. New York: Prentice Hall.

Mintzberg H (1989). Mintzberg on Management: Inside our Strange World or Organisations. New York: Prentice Hall.

Mintzberg H (2004). Managers not MBAs. A Hard Look at the Soft Practice of Managing and Management Development. San Francisco: Barrett-Koehler Publishers, Inc.

Morrell K and Learmouth M (2017). Evidence Based Management. In Wilkinson A et al (Eds.) The Oxford Handbook of Management. Oxford: Oxford University Press.

Nonaka I (2007). The Knowledge Creating Company. Brighton: Harvard Business Review Press.

Olson JP (2006). Maybe it is time to rediscover bureaucracy. Journal of Public Administration Research and Theory, 16: 1-24.

Oswick C, Keenoy T and Grant D (1997). Managerial discourses: Words speak louder than actions. Journal of Applied Management Studies, 6(1): 5-12.

Pedersen JS (2007). Appendix 1: Questions to managers of public institutions in Denmark and answers in a national survey. In Pedersen JS (Ed.) Ledelse i en reformtid i velfærdsstatens maskinrum. Copenhagen: Danmarks Forvaltningshøjskole: 165 - 176.

Pedersen JS (2010). Reformer i den offentlige sektor - skab seks plusser. Copenhagen: Juristog Økonomforbundets Forlag.

Pedersen JS and Aagaard P (2015). Dirigent eller dukke - lederen i reformstaten. Copenhagen: Gyldendal.

Pedersen JS (2016). Ledelse af fagprofessionelle. In Aagaard P and Agger A (Eds.) Ledelse i politisk styrede organisationer. Copenhagen: Hans Reitzels Forlag: 261 - 298.

Pedersen JS (2017). Summary of Interviews (May/June 2016) regarding Data-DrivenManagement at Hospitals in the Capital Region in Denmark. Paper in progress.

Pedersen JS and Nielsen AL (2014). Has the competition among professionals in the Nordic welfare states intensified? The Danish Case. Nordicum-Mediterraneum, 9(3): 19 p.

Polanyi M (1966). The Tacit Dimension. Chicago: University of Chicago Press.

Power M (1997). The Audit Society. Oxford: Oxford University Press.

Provost F and Fawcett T (2013). Data science and its relationship to big data and data-driven decision making. Big Data 1(1): 51-59. 
Rousseau DM and Barends EGR (2011). Becoming an evidence-based HR practitioner. Human Resource Management Journal, 21: 221-235.

Riccucci NM (2005). How Management Matters: Street-Level Bureaucrats and Welfare Reform. Washington: Georgetown University Press.

Røvik KA (2002). The Secrets of the Winners: Management Ideas that Flows. In SahlinAnderson K and Engwall L (Eds.) The Expansion of Management Knowledge: Carriers, Flows and Sources. Standford Business Books: 113 - 144.

Schön D (1991). The Reflective Practitioner. Aldershot: Ashgate Publishing Ltd

Strauss AL, Schatzman R, Bucher D, Ehrlich and Sabshin M (1964). Psychiatric Institutions and Ideologies. Glencove, NY: Free Press.

Thornton P, Ocasio W and Lounsbury M (2012). The Institutional Logics Perspective: A New Approach to Culture, Structure and Process. Oxford: Oxford University Press.

van Buuren A, Gerrits L and Marks P (2009). Public Policy-Making and the Management of Coevolution. In Teisman GR, van Buuren A and Gerrits L (Eds.) Managing Complex Governance Systems: Dynamics, Self-Organization and Coevolution in Public Investment. Routledge.

Whelan C (2012). Big data and the democratisation of decisions. The Economist Unit report.

Wilkinson A, Hislop and Coupland C (Eds.) (2015). Perspectives on Contemporary Professional Work. Cheltenham: Elgar Press.

Winther SC and Nielsen VL (2008). Implementering af politik. Aarhus: Academia. 
